\title{
Modelling And Study Of Chip Tool Interactions With High Velocity Air Jet As Cooling Media
}

\author{
Mr. Balamurali, Dr. C.L.V.R.S.V. Prasad, Mr. C. Yesaswi Narendra \\ PG Student, Dept of Mech. Eng., GMR Institute of Technology Rajam, Srikakulam, A.P, India \\ Professor, Dept of Mech. Eng., GMR Institute of Technology Rajam, Srikakulam, A.P., India. \\ UG Student, Dept of Mech. Eng, IIT Patna, Bihar, India
}

\begin{abstract}
Introduction Of Green Concepts In Machining Operations Is Being Envisaged By Introducing Different Echo Friendly Cooling Systems In The Modern Machine Shops. The Role Of Cutting Fluids Usage In Metal Cutting Is Predominant As It Influences The Surface Quality And Production Cost. More Over Disposal Of The Cutting Fluid Mainly Effects The Environment. The Current Work Mainly Focuses On The Study Of Chip Tool Interactions Viz. Contact Pressure, Stress Distribution On The Rake Surface In Plain Turning Operation For Different Cutting Parameters With High Velocity Air Jet As A Cooling Medium. Chip Tool Contact Pressure Is Estimated Using Fem Tools And The Influence Of The High Velocity Air Jet On Contact Pressure Is Studied By Simulating The Flow Patterns Of The High Velocity Air Jet Using Cfd Tools.
\end{abstract}

Keywords: - Modeling; Machining; Dynamometer; Prole; Ansys; CFD, CFX

\section{INTRODUCTION}

The use of high speed air jet as a coolant in machining is a challenging scenario in environmental friendly machining. Despite the extensive literature, air jet cooling in machining is an area of ongoing research. Until now, the jet cooling technique has been studied only from a thermal point of view. The new aspect investigated in this work is the chip bending ability of the jet and the influence on the chip tool contact pressure. The idea of chip-bending and its beneficial effects in cooling the cutting area is not related to maximizing the heat transfer, but to avoid the temperature increase. The heat generation in the chip-tool interface is due to the contribution of deformation in the shear zone and to the frictional contact between the chip and the rake face of the cutting tool. The importance of the frictional contact is proportional to the friction coefficient and to the pressure of the chip on the rake face. The traditional way of reducing this contribution is using a cutting fluid (flooding) or, more recently, injecting a coolant in the chip-tool interface.

\section{METHODOLOGY}

The new approach with high speed air jet shows the temperature reduction is strongly dependant on the position of the nozzle. By directing the high velocity air jet in between the rake face and chip, it is possible to reduce the chip pressure on the rake face, which is responsible of temperature increase in the chip-tool interface. The cutting pressure on the top face of the chip generates high at the chip-tool interface. The overall net pressure on the rake face will be due to air jet pressure and cutting pressure on the rake face which are opposing each other. When the air jet is directed between the rake face and the chip the net stress on the rake face shall be less when compared with the cutting stress in dry machining.

To compare the contact pressrue under complete dry machining conditions and with that using high velocity air jet as a cooling media,a 3D model of the cutting tool is developed using Pro/e and the stresses induced on the rake face with different maching conditions are simulated using ANSYS.. From an analytical point of view the chip and the tool bit can be modeled as a structural cantilevered beam with uniform load. The influence of high velocity air jet at the chip tool interface is simulated using CFD tools and the flow patterns of the high velocity airjet are depicted. .

\section{EXPERIMENTATION}

The effect of the cutting parameters like cutting speed, feed rate and depth of cut on cutting force components which influence the contact pressure, temperature and chip flow pattern on the rake surface during turning operation is studied by conducting experiments under dry machining conditions.

\section{- Experimental Setup}

The experimental setup to find the cutting forces for different speeds feeds and depth of cuts is shown in fig.1. The assembly of the tool holder on the dynamometer is shown in the fig.2. Through the data acquisition system the dynamometer measures the cutting forces under different machining conditions. 
The results are carefully tabulated and are used for the analysis of the cutting tool. Stress distribution on the rake face of the tool is found based on the cutting forces that are measured from the dynamometer.

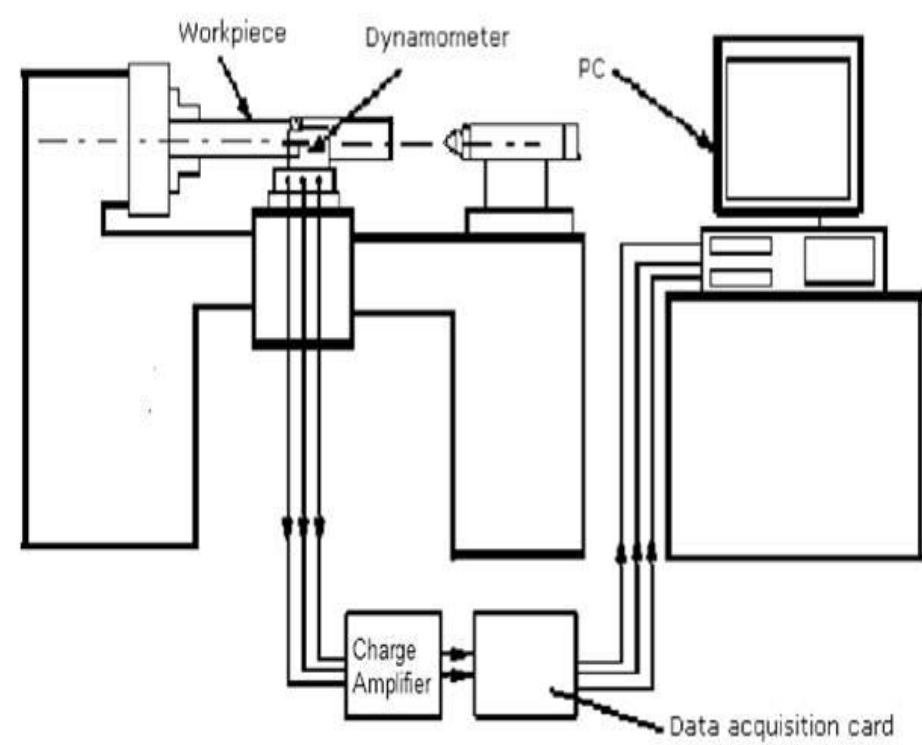

Fig 1: Schematic diagram of the experimental setup.

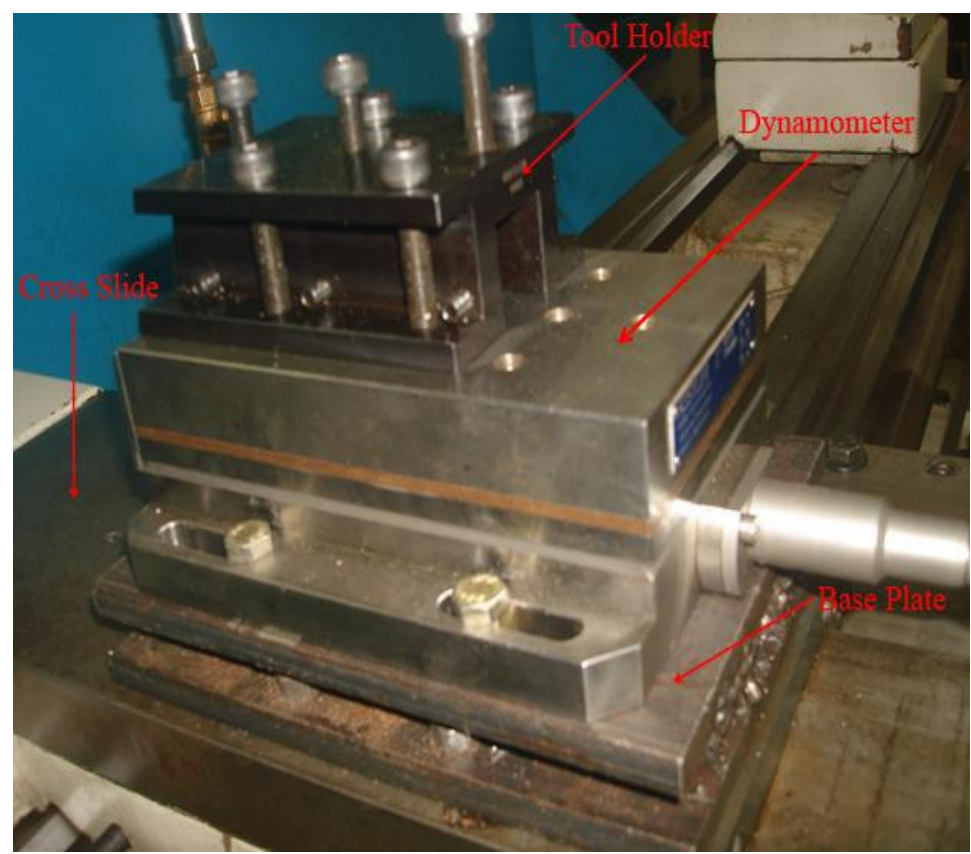

Fig 2: Experimental setup for finding the cutting forces

Initial diameter of the bar $=25 \mathrm{~mm}$

- Properties of Job and tool materials

Bar material $=$ MS(Mild steel $)$

Cutting tool material $=$ HSS $($ High speed steel) $[2]$

Material : High Speed Steel

Young's modulus : : 190-210Gpa

Poisson's ratio $\quad: \quad 0.27$

Density : $\quad 7800 \mathrm{~kg} / \mathrm{m} 3$

Work piece : $\quad$ Mild steel 
Table 1: Cutting forces without coolant

\begin{tabular}{|c|c|c|c|}
\hline Speed (rpm) & Feed (mm/rev.) & Depth of Cut (mm) & Cutting Force (N) \\
\hline 550 & 0.1 & 0.1 & 23.88 \\
\hline 440 & 0.1 & 0.1 & 17.73 \\
\hline 330 & 0.1 & 0.1 & 13.96 \\
\hline 220 & 0.1 & 0.1 & 22.20 \\
\hline 118 & 0.1 & 0.1 & 14.57 \\
\hline 118 & 0.2 & 0.1 & 20.82 \\
\hline 220 & 0.2 & 0.1 & 21.29 \\
\hline 330 & 0.2 & 0.1 & 19.03 \\
\hline 440 & 0.2 & 0.1 & 30.97 \\
\hline 550 & 0.2 & 0.1 & 16.86 \\
\hline 550 & 0.3 & 0.1 & 67.59 \\
\hline 440 & 0.3 & 0.1 & 44.51 \\
\hline 330 & 0.3 & 0.1 & 36.31 \\
\hline 220 & 0.3 & 0.1 & 23.68 \\
\hline 118 & 0.3 & 0.1 & 62.86 \\
\hline 118 & 0.4 & 0.1 & 46.04 \\
\hline 220 & 0.4 & 0.1 & 44.63 \\
\hline 330 & 0.4 & 0.1 & 24.71 \\
\hline 440 & 0.4 & 0.1 & 28.83 \\
\hline
\end{tabular}

IV. ESTIMATION OF THE CHIP TOOL CONTACT LENGTH

A number of theoretical and experimental estimators have been proposed for the contact length in the orthogonal cutting process Based on the experiments conducted on different types of steel using a tool with an unrestricted rake face, a relationship between the chip-tool contact length, chip thickness, the chip compression ratio and the friction coefficient has been developed. It suggests that the length of the sticking region is approximately equal to the deformed chip thickness hc, and in accordance with Tay's assumption[3]

Total chip-tool contact length Lc as shown in the Figure 3 is given as [4]

Lc : $2 \mathrm{hc}$

Thickness of the chip: $\quad 1.5 \mathrm{~mm}$

Width of the chip : $\quad 4 \mathrm{~mm}$

Contact Length : $\quad 2 * 1.5=3 \mathrm{~mm}$

Area of the chip contacting the tool $=3 * 4=$

$12 \mathrm{~mm}^{2}$

Pressure acting on the contact area $=$ Force/Area

P1 $=23.88 / 12 \quad=1.99 \mathrm{~N} / \mathrm{mm}^{2}$

Similarly for the remaining forces

$\begin{array}{ll}\text { P2 } & =1.419 \mathrm{~N} / \mathrm{mm}^{2} \\ \text { P3 } & =1.163 \mathrm{~N} / \mathrm{mm}^{2} \\ \text { P4 } & =1.85012 \mathrm{~N} / \mathrm{mm}^{2} \\ \text { P5 } & =1.214 \mathrm{~N} / \mathrm{mm}^{2}\end{array}$

P5 $=1.214 \mathrm{~N} / \mathrm{mm}^{2}$

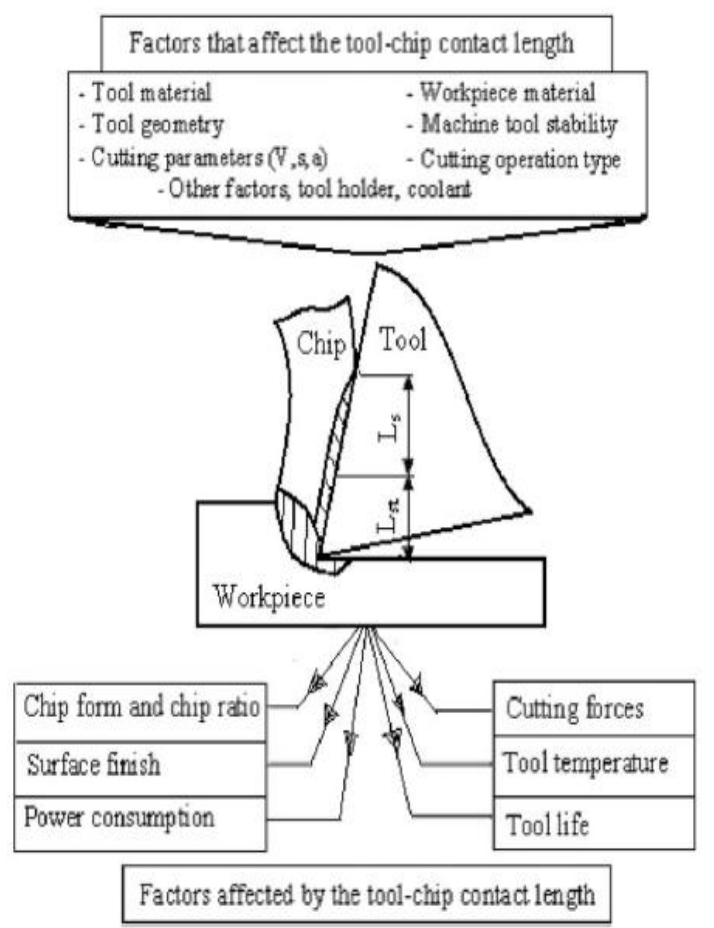

Fig 3: Chip Tool contact length 


\section{STRESS ANALYSIS OF CUTTING TOOL WITHOUT COOLANT \\ VI. FOR THE SPEED (N) : 550 RPM, \\ VII. FEED $: 0.1 \mathrm{MM} / \mathrm{REV}$, \\ VIII. DEPTH OF CUT $\quad$ 0.1MM}

For applying the load that is pressure first choose the area that the chip is in contact with the tool .Then apply the load on that area as in the Figure 4

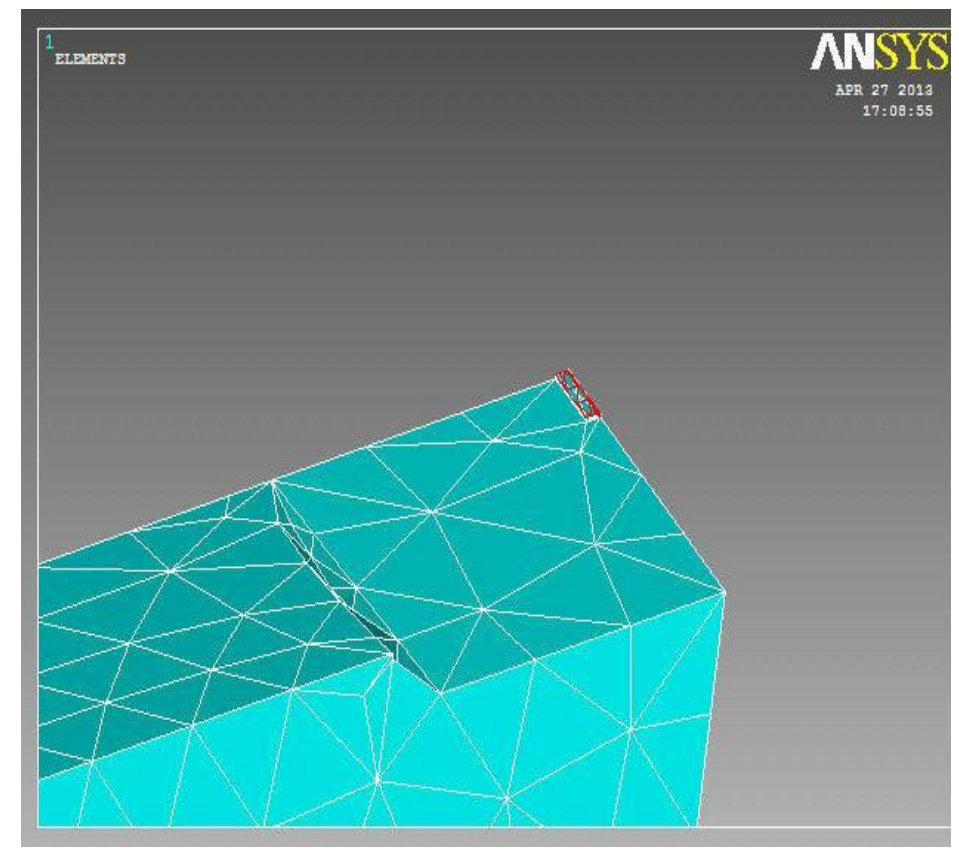

Fig 4: Area selection for applying the load of cutting tool

After load is applied by giving the material properties and constraints on the selected area, deformation and stresses are developed.The required Von misses stresses are show in the Figure 5

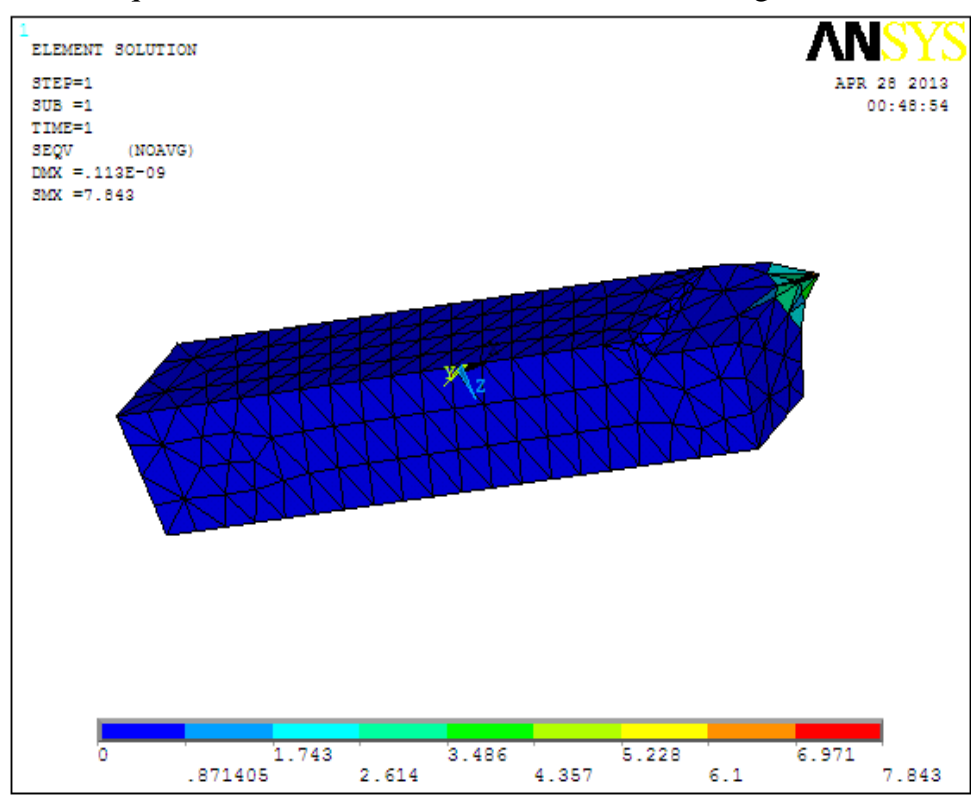

Fig5 VonMisses Stresses of cutting tool

Maximum Stress is $3.21 \mathrm{~N} / \mathrm{mm}^{2}$.

Now for another different set of speed, feed and depth of cut Von misses stresses are taken by using ansys and are shown in the below Figure 6. 


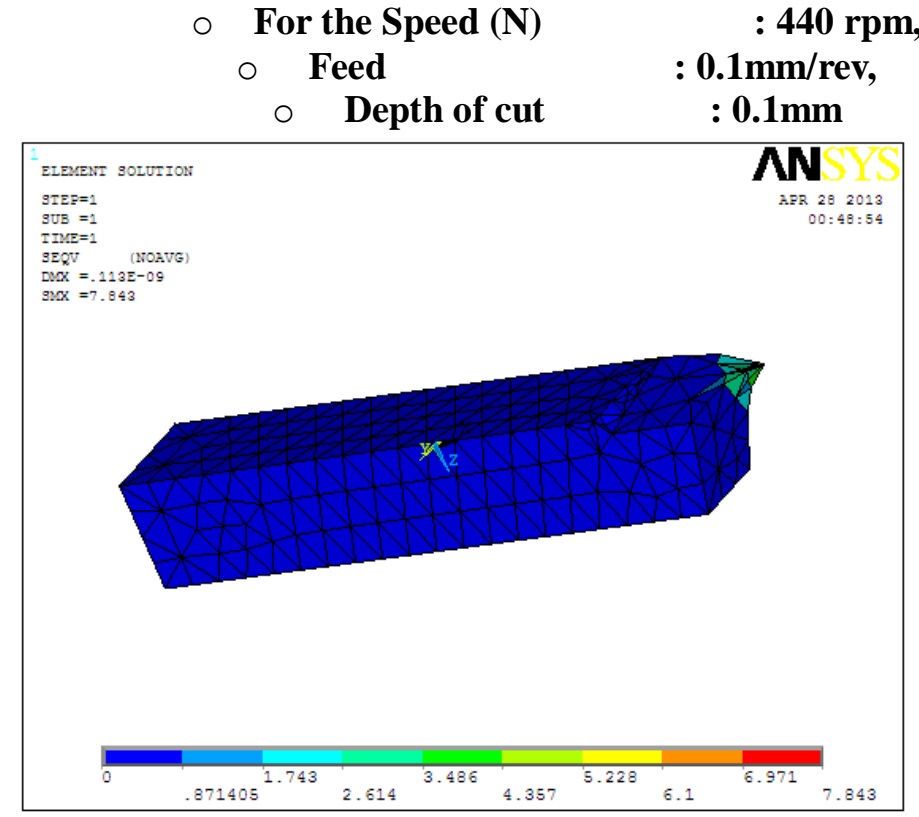

Fig 6: $\quad$ Von misses stresses for cutting tool

Maximum Stress $2.289 \mathrm{~N} / \mathrm{mm}^{2}$

In figure6 shows the Von Misses stresses for the another set of speed feed and depth of cuts
○ For the Speed (N)
$\circ$ Feed
○ Depth of cut
: $330 \mathrm{rpm}$,
: $0.1 \mathrm{~mm} / \mathrm{rev}$,
: $0.1 \mathrm{~mm}$

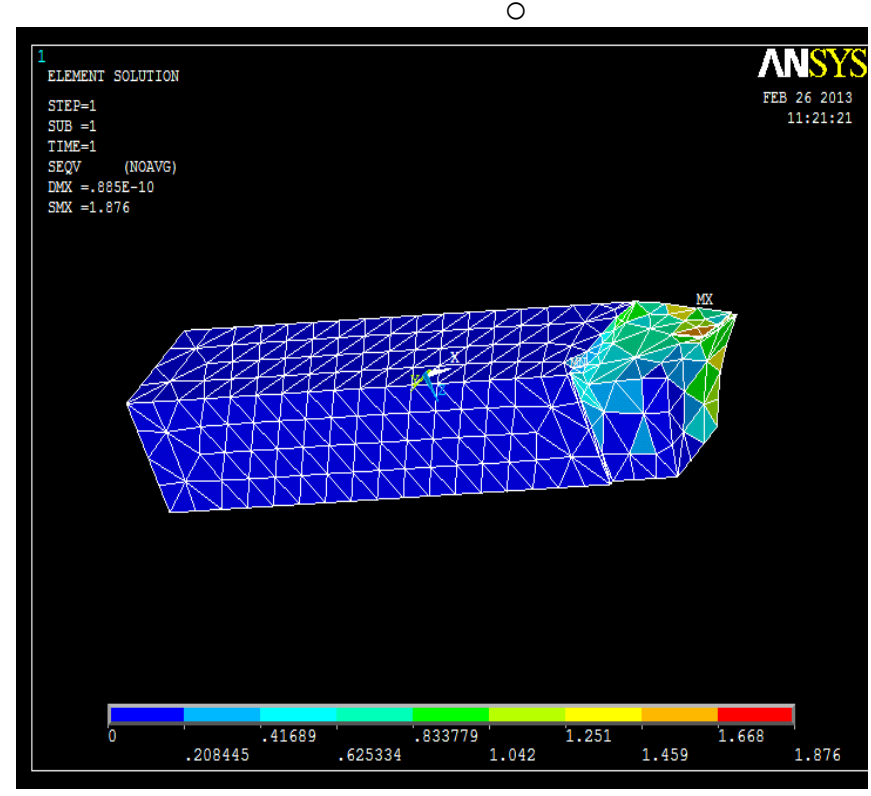

Fig 7: Von misses stresses for cutting tool

Maximum stress is $1.876 \mathrm{~N} / \mathrm{mm}^{2}$

A plot showing the variation of Contact pressures Vs Stress for different machining condition indicates that the variation linear as shown in the Figure 8 


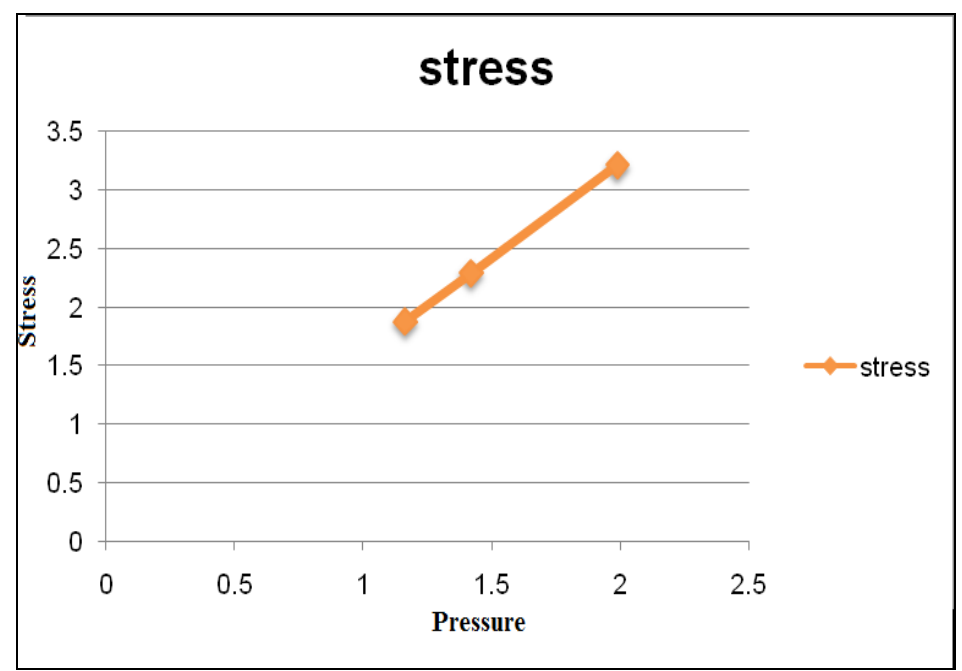

Fig 8:Pressure Vs. Stress Graph

Taylor Tool Life Equation [1]

IX. TOOL LIFE

$$
\mathrm{VT}^{\mathrm{n}}=\mathrm{C}
$$

Where $\mathrm{v}=$ cutting speed, $\mathrm{m} / \mathrm{min}$;

$\mathrm{T}=$ tool life, $\min$;

$\mathrm{n}$ and $\mathrm{C}$ are parameters that depend on feed, depth of cut,work material, and tooling material but mostly on material (work and tool).

○ Table 2: $\quad$ Typical Values of $\mathbf{n}$ and $\mathbf{c}$

\begin{tabular}{|l|c|c|}
\hline Tool material & n & C \\
\hline High Speed Steel & & \\
Non Steel Work & 0.125 & 120 \\
Steel Work & 0.125 & 70 \\
\hline Cemented & & \\
carbide & 0.25 & 900 \\
Non Steel Work & 0.25 & 500 \\
Steel Work & & \\
\hline Ceramic & & \\
Steel Work & 0.6 & 3000 \\
\hline
\end{tabular}

Cutting velocity $\quad: \pi \mathrm{DN} / 1000(\mathrm{~m} / \mathrm{min})$

D $\quad$ : Spindle diameter $(\mathrm{mm})$

Sample calculation :

$$
\mathrm{V} 1=\pi \times 25 \times 550 / 1000=43.19 \mathrm{~m} / \mathrm{min}
$$

Similarly

$\mathrm{V} 2=34.55 \mathrm{~m} / \mathrm{min}$

$$
\mathrm{V} 3=25.19 \mathrm{~m} / \mathrm{min}
$$

$\mathrm{V} 4=17.29 \mathrm{~m} / \mathrm{min}$

Since $\mathrm{VT}^{\mathrm{n}}=\mathrm{C}$

$$
\begin{aligned}
\mathrm{T} 1 & : \\
& (70 / 43.19)(1 / 0.125) \\
& 49.32 \mathrm{~min}
\end{aligned}
$$

Similarly

$$
\mathrm{T} 2=\quad 283.92 \mathrm{~min}
$$

$\mathrm{T} 3=\quad 2838.2 \mathrm{~min}$

$\mathrm{T} 4=\quad 72.85 \times 103 \mathrm{~min}$ 


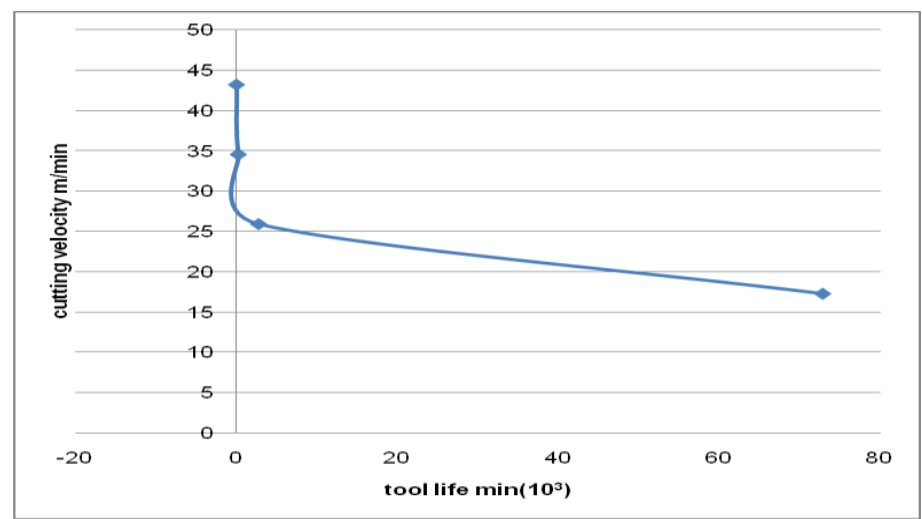

Fig 9: Cutting speed Vs Tool Life

The plot between the cutting speed and Tool life depicts that tool life varies in parabolic shape. As the cutting speed increases tool life decreases as cutting speed decreases tool life increases and tool life slightly decreases at low cutting speeds which is as shown in the Figure 9

\section{CFD ANALYSIS FOR AIR JET FLOW PATTERN}

Assumptions made for CFD for analysis

- Assuming tool as flat surface

- Assuming chip as regular shape i.e rectangular

3D modelling of the experimental setup:

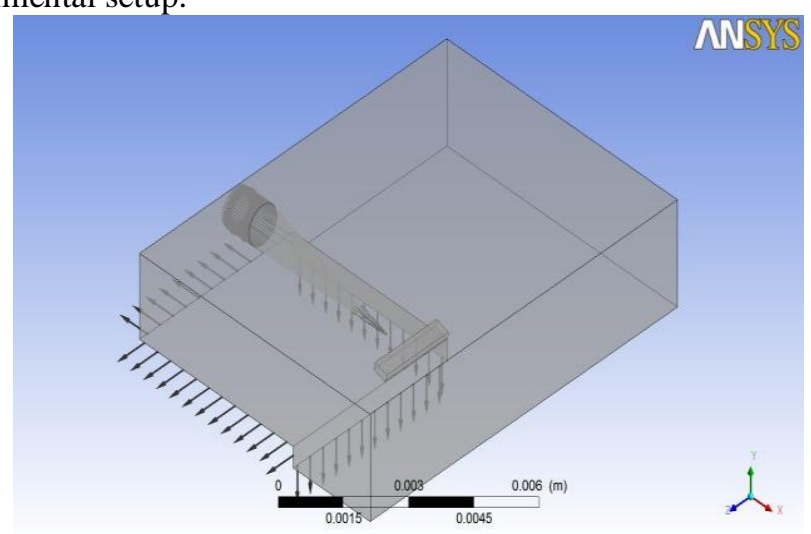

Fig10: 3D Model of the setup

Figure 10 shows $3 \mathrm{~d}$ experimental setup which is considered by taking the following assumptions.

Analysis of jet flow for $20 \mathrm{~m} / \mathrm{s}$

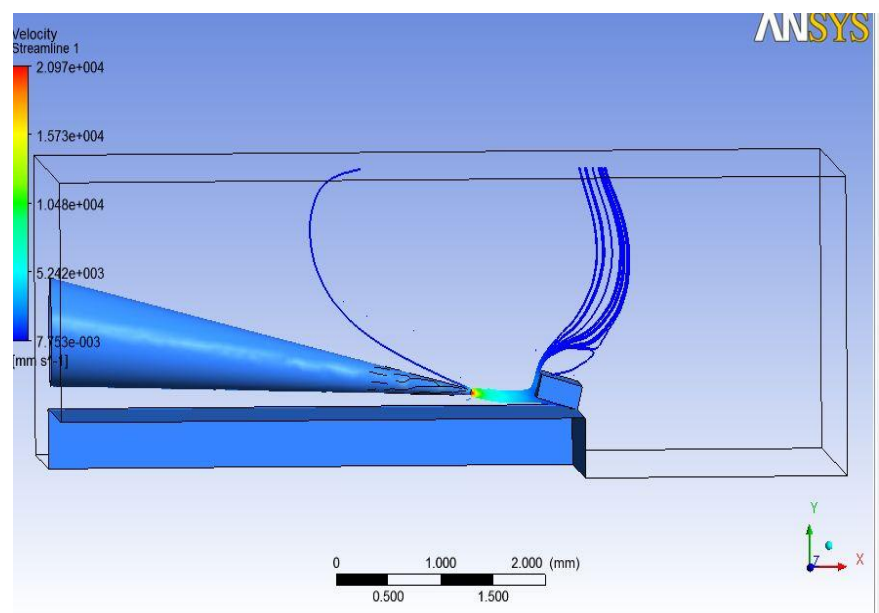

Fig11: Stream line at inlet of nozzle 
Figure. 11 represents the stream line flow of the jet at the inlet of the nozzle. This flow shows the jet flow between chip and tool

Velocity vector of the jet coming from the nozzle:

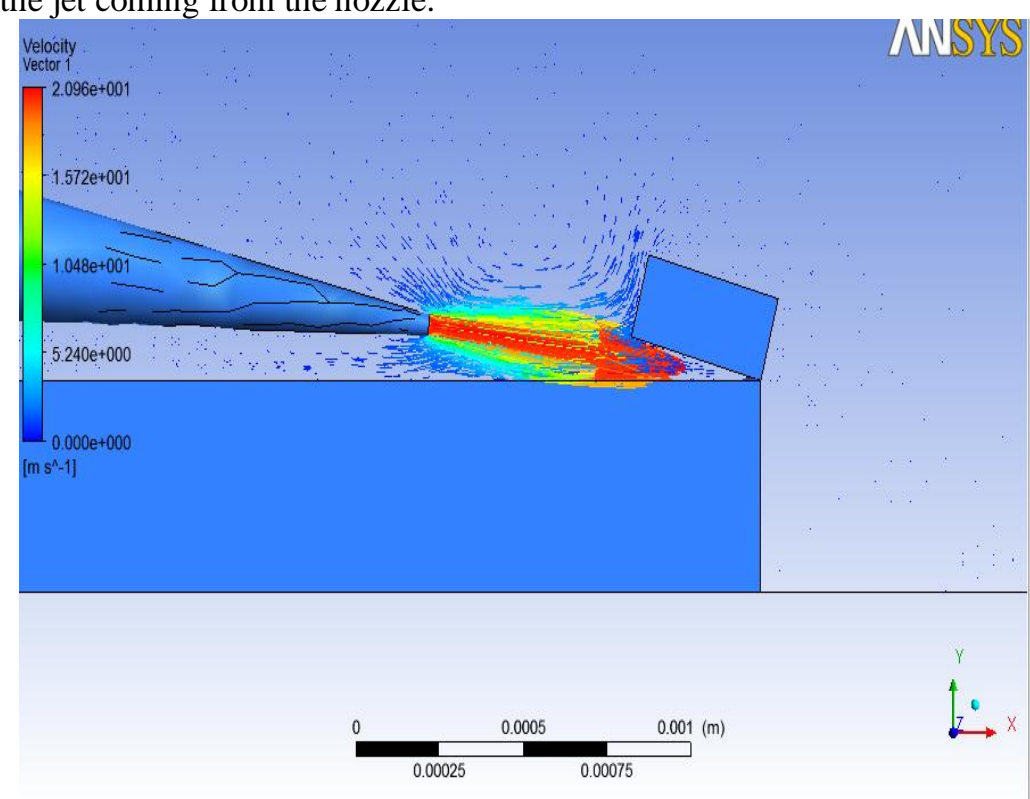

Fig12: velocity vector

Figure 12 shows the velocity vector of the flow coming from the nozzle. By this clearly knowing that the jet is passing between the tool and chip

Velocity stream line on a plane:

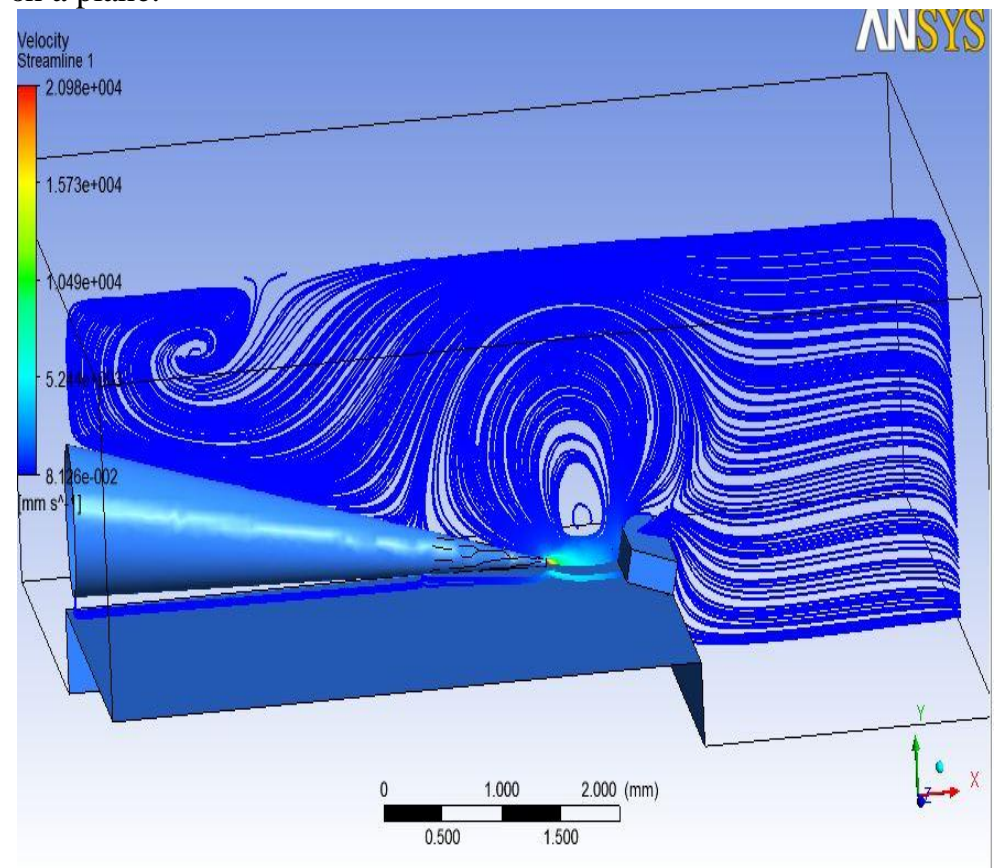

FIG13: Velocity stream line

Figure 13 shows the velocity stream line on the plane 
Flow pattern of the jet when entered between chip and tool

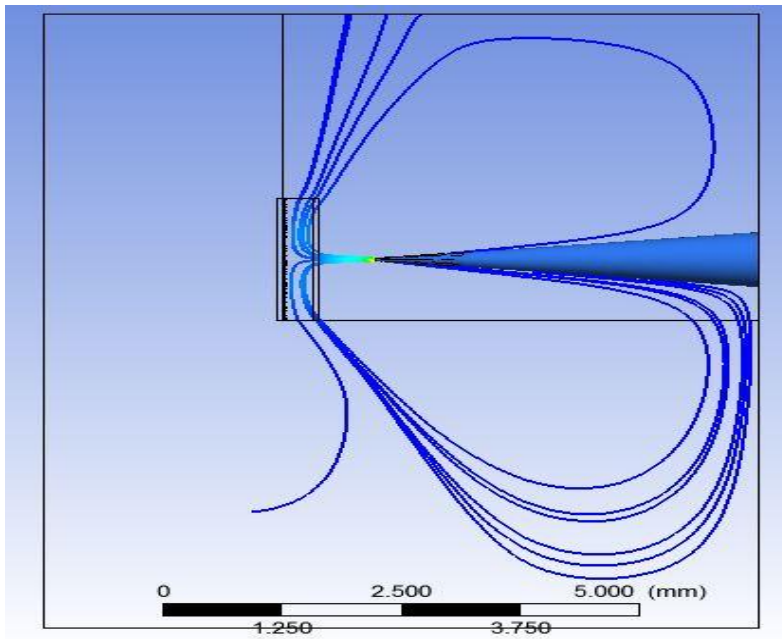

Fig14: Flow pattern of the jet

Pressure pattern at inlet

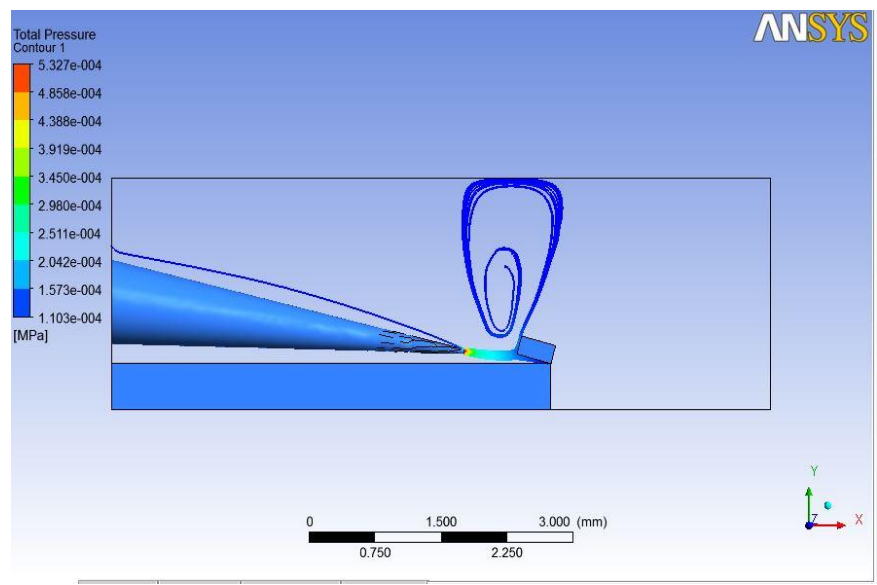

Fig15: Pressure pattern at in let

Figure15 shows the pressure pattern at inlet during flow. The pressure that is developed at the inlet is equal to the $480 \mathrm{~Pa}$.

Pressure pattern at inlet for $50 \mathrm{~m} / \mathrm{s}$ :

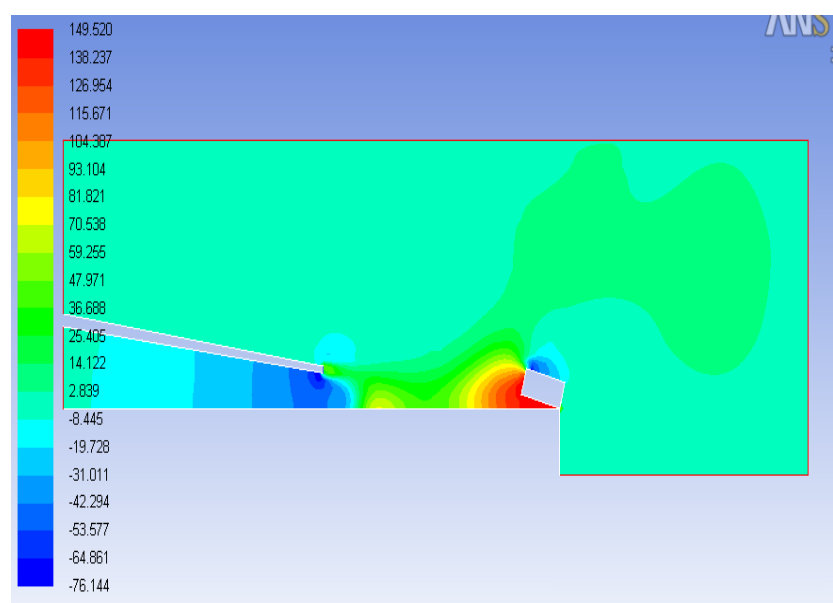

FIG15: Pressure profile

Figure 15 shows the pressure profile at $50 \mathrm{~m} / \mathrm{s}$ 


\section{COMPARISON OF PRESSURE WITH AND WITHOUT COOLANT}

Pressure acting on the contact area $=$ Force/Area

$\mathrm{P} 1=23.88 / 12 \quad=1.99 \mathrm{~N} / \mathrm{mm}^{2}$

Similarly for the remaining forces

$\mathrm{P} 2=1.419 \mathrm{~N} / \mathrm{mm}^{2}$

P3 $=1.163 \mathrm{~N} / \mathrm{mm}^{2}$

$\mathrm{P} 4=1.85012 \mathrm{~N} / \mathrm{mm}^{2}$

P5 $=1.214 \mathrm{~N} / \mathrm{mm}^{2}$

In this maximum pressure is $1.99 \mathrm{~N} / \mathrm{mm} 2$

From the CFD analysis, it is observed that the high velocity jet impinging with a velocity of $50 \mathrm{~m} / \mathrm{s}$ between chip and tool develops a pressure of $6.5 \mathrm{~N} / \mathrm{mm} 2$ which is sufficient to lift the chip over the rake face leading to reduction of contact pressure and hence the tool wear.

\section{CONCLUSION}

Modelling and analysis of cutting tool in the turning operation without cutting fluid i.e. in dry cutting mode is done with the data available in the literature with regard to the cutting forces acting on the rake face. Further with reference to these cutting forces and chip dimensions that are obtained in case of turning operation configuration for experimentation is assumed for CFD analysis with the help of ICEM soft ware and analysis is done with the CFX tool .By this analysis flow pattern of the air jet and pressures are determined and its influence on pressure between tool and chip. For the given air jet properties the pressure between the chip and rake face is found to be about $6.5 \mathrm{~N} / \mathrm{mm}^{2}$ which is sufficient to lift the chip and float over the rake. As the chip floats on the rake face due to the high velocity air jet, contact area is reduced so that stresses are reduce and in turn reduces the tool wear and increases the tool life during machining.

\section{REFERENCES}

[1]. Leone, W.C.; "Distribution of shear zone heat in metal cutting"; Transactions of ASME, vol. 76, pp. 121 125,1954

[2]. Adibi-Sedeh, A.H., Madhavan, V., Bahr, B.; "Extension of Oxley's analysis of machining to use different material models"; ASME Journal of Manufacturing Science and Engineering, vol.125, pp.656-666, 2003

[3]. Leowen, E.G., Shaw, M.C.; "On the analysis of cutting tool temperatures"; Transactions of ASME, vol.71, pp.217-231, 1954

[4]. Jaeger, J.C.; "Moving sources of heat and the temperatures of sliding contacts"; Proceedings of Royal Society N.S.W., vol.76, pp.203-204, 1942

[5]. Smithey, D.W., Kapoor, S.G., DeVor, R.E.; "A new mechanistic model

[6]. For predicting worn tool cutting forces"; Machining science and Technology, vol.5/1, pp.23-42, 2001

[7.] Shaw, M.C.; "Metal Cutting Principles"; 1984; ISBN 0-19-859020-2 